\title{
Sex Differentiation in Amphibians: Effect of Temperature and Its Influence on Sex Reversal
}

\author{
Adrián Ruiz-García Álvaro S. Roco Mónica Bullejos \\ Departamento de Biología Experimental, Facultad de Ciencias Experimentales, Universidad de Jaén, Jaén, Spain
}

\section{Keywords}

Amphibian · GSD · Sex determination/differentiation · Sex

reversal $\cdot$ Temperature

\begin{abstract}
The role of environmental factors in sexual differentiation in amphibians is not new. The effect of hormones or hormonelike compounds is widely demonstrated. However, the effect of temperature has traditionally been regarded as something anecdotal that occurs in extreme situations and not as a factor to be considered. The data currently available reveal a different situation. Sexual differentiation in some amphibian species can be altered even by small changes in temperature. On the other hand, although not proven, it is possible that temperature is related to the appearance of sex-reversed individuals in natural populations under conditions unrelated to environmental contaminants. According to this, temperature, through sex reversal (phenotypic sex opposed to genetic sex), could play an important role in the turnover of sex-determining genes and in the maintenance of homomorphic sex chromosomes in this group. Accordingly, and given the expected increase in global temperatures, growth and sexual differentiation in amphibians could
\end{abstract}

easily be affected, altering the sex ratio in natural populations and posing major conservation challenges for a group in worldwide decline. It is therefore particularly urgent to understand the mechanism by which temperature affects sexual differentiation in amphibians.

(c) 2021 S. Karger AG, Basel

The dichotomous and mutually exclusive interpretation of environmental and genetic sex determination mechanisms (ESD and GSD mechanisms, respectively) has changed in the last decade. Under the current view, the interaction between the genotype and the environment is integrated to model sex determination and differentiation in ectotherms. This new approach has been made possible by experimental observations on the effect of temperature mainly in reptiles and fish.

During this change of paradigm, amphibians have been left behind. The effect of temperature on gonadal differentiation has been considered to be a side effect of growing tadpoles under extreme conditions but not

\section{A.R.-G. and Á.S.R. contributed equally to this work.}

Correspondence to:

Mónica Bullejos, bullejos@ujaen.es 
something to worry about in natural conditions. Furthermore, the identification of sex-reversed individuals is hampered in a group characterized by homomorphic sex chromosomes and a lack of knowledge on the sex-determining genes. As a consequence, information about the role of temperature on gonadal differentiation is scarce in this group. This review will update our current knowledge on amphibian sex chromosomes and sex determination, integrating the available experimental evidence on the effect of temperature on gonadal differentiation not included in previous reviews [Hayes, 1998; Wallace et al., 1999; Eggert, 2004; Flament, 2016; Miura, 2017].

\section{Amphibian Sex Chromosomes and Sex Determination}

Amphibians constitute an interesting group with a variety of reproductive modes and an impressive flexibility in gonadal and sexual differentiation. According to AmphibiaWeb (https://amphibiaweb.org; accessed May 3, 2021), there are 8,233 amphibian species [7,352 frogs and toads (order Anura), 764 newts and salamanders (order Caudata), and 214 caecilians (order Gymnophiona)]. These numbers are in contrast with our scarce knowledge about the sex chromosomes, the sex-determining genes, and the gene regulatory networks involved in sexual differentiation operating in this class, where caecilians are still an unknown order when considering these (and many others) questions.

\section{Sex Chromosomes}

It is widely accepted that amphibian sex determination is genetically controlled [Hayes, 1998; Wallace et al., 1999; Eggert, 2004; Flament, 2016; Miura, 2017]. However, heteromorphic sex chromosomes have only been described in $4-5 \%$ of the species that have been analysed [Schmid and Steinlein, 2001; Eggert, 2004; Schmid et al., 2010]. Proving genetic control of sex determination in species with homomorphic sex chromosomes is not straightforward. Nonetheless, in this group, it can easily be done by analysing the sex ratios of the offspring produced by gynogenesis or from crosses that involve sex-reversed individuals [Chang and Witschi, 1956; Mikamo and Witschi, 1964].

Both male (XX/XY) and female (ZZ/ZW) heterogamety can be found in amphibian species, although male heterogamety is more frequent. Phylogenetic analysis suggests that the ancestral form was XX/XY [Hillis and Green, 1990], although numerous sex chromosome tran- sitions have been identified even in closely related species [Furman and Evans, 2018; Jeffries et al., 2018]. An extreme case of variation in sex chromosomes has been described in a single species, Rana rugosa, where chromosomal inversions together with hybridization events gave rise to 6 geographic variants with both XX/XY and ZZ/ ZW sex chromosome systems [Ogata et al., 2002, 2018; Oike et al., 2017b]. Another example of intraspecies transition may occur in Xenopus tropicalis. The coexistence of 3 sex chromosomes $(\mathrm{Y}>\mathrm{W}>\mathrm{Z})$ in laboratory strains of this species reveals that male (YW and YZ) and female heterogamety ( $\mathrm{ZW})$ is possible in the lab [Roco et al., 2015]. Natural populations of $X$. tropicalis from Ghana also have $\mathrm{Y}, \mathrm{Z}$, and $\mathrm{W}$ sex chromosomes, and nucleotide polymorphisms of expressed transcripts suggest that the Y chromosome has emerged from an ancestral Z chromosome [Furman et al., 2020]. In this regard, thorough analysis of natural populations can be very informative. In R. temporaria (XX/XY), for example, natural populations reveal differences in the degree of genetic differentiation between $\mathrm{X}$ and $\mathrm{Y}$ chromosomes [ranging from differentiated Y chromosomes in XY males with strict GSD to undifferentiated sex chromosomes in XX males (no GSD)] related to different Dmrt1 haplotypes [Phillips et al., 2020].

Other sex chromosome oddities are also found in amphibians. The 00/W0 sex chromosome system in Leiopelma hochtetteri, with a distinctive supernumerary $\mathrm{W}$ chromosome not present in males [Green, 1988], is an interesting example.

\section{Sex-Determining Gene and Sex Differentiation \\ Pathway}

The molecular mechanisms by which sex is determined in amphibians are largely unknown, partly because of the difficulty in finding the pair of sex chromosomes. Only one sex-determining gene is known in this group: the $d m-w$ gene (DM domain-containing W-link) in X. laevis [Yoshimoto et al., 2008], a species with an allotetraploid origin and homomorphic ZZ/ZW sex chromosomes [Mikamo and Witschi, 1966]. The $d m-w$ gene was originated by a partial duplication of $d m r t 1 . S$ (lacks the transactivation domain) and is now located on chromosome pair 2L [Yoshimoto et al., 2008; Bewick et al., 2011; Mawaribuchi et al., 2017]. The overexpression of $d m-w$ can induce female differentiation in ZZ tadpoles, while $d m$ - $w$ knockdown can cause female-to-male sex reversal in ZW [Yoshimoto et al., 2008, 2010]. It has been proposed that $d m$-w functions as a dominant-negative form of $d m r t 1$, antagonizing testis formation promoted 
by $d m r t 1$ and resulting in high expression of $c y p 19 a 1$ and foxl2 [Okada et al., 2009].

Androgen receptor $(A R)$ also has been proposed to have a critical role in sex determination in R. rugosa. It is located on the sex chromosomes $(Z, \mathrm{~W}, \mathrm{Y}$, and $\mathrm{X})$ of this species [Uno et al., 2008], and the low level of expression of the $\mathrm{W}$-linked $A R$ compared to the $\mathrm{Z}$ - $A R$ suggests a key role in sex determination [Yokoyama et al., 2009]. However, ZW tadpoles with the Z-AR transgene are not fully sex-reversed (develop ovotestes) unless low levels of testosterone, not sufficient to induce sex reversal in $\mathrm{ZW}$ female tadpoles, are added to the rearing water [Fujii et al., 2014]. Furthermore, $\mathrm{ZW}$ tadpoles with the $A R$ gene disrupted by CRISPR/Cas9 editing do not reverse their sex at high testosterone levels, although ZW females do [Oike et al., 2017a].

Two other sex-related genes, sf 1 and sox 3 , are located on the sex chromosomes of $R$. rugosa [Uno et al., 2008]. However, it remains unclear which gene is required for sex determination in this species. The answer can be complex, considering the results from hybrids between different populations. The origin of heteromorphic $\mathrm{Y}$ and $\mathrm{Z}$ or $\mathrm{X}$ and $\mathrm{W}$ sex chromosomes can be traced back to chromosome 7 of West Japan and East Japan groups, respectively [Miura et al., 1998; Ogata et al., 2002, 2008]. Although the same chromosome pair is the sex chromosome in all of the populations, it is possible that different sex-determining genes have evolved in different populations. In fact, reciprocal hybrids between males and females of the northern (ZZ/ZW, Murakami) and southern (XX/XY, Hamakita) populations show interesting sex ratios for some chromosome combinations [Nishioka and Hanada, 1994]. All hybrids between XX females and ZZ males have ZX sex chromosomes, but the sex ratio in mature offspring is close to $1: 1$ ( $53 \%$ females, $n=330$ ). Reciprocal cross $(\mathrm{ZW} \times \mathrm{XY})$ is also interesting. $\mathrm{ZY}$ and $\mathrm{WX}$ animals are males and females, respectively, while WY are mostly females $(96.5 \%, n=55)$ and ZX are males or females. These results indicate that the female-determining gene located on the $\mathrm{W}$ is dominant over the male-determining gene on the Y (WY individuals have a female phenotype). Furthermore, in the absence of a dominant master sexdetermining gene (ZX), the gene regulatory network for sex determination could randomly choose between the mutually exclusive male or female pathways [Perrin, 2016].

Sex determination in amphibians can be complex and could include autosomal factors or other sex-linked genes, which can be revealed under experimental situations. This is the case of triploid individuals of the Japa-

Effect of Temperature in Amphibian Sex

Differentiation nese frog Buergeria buergeri. This species has ZZ/ZW heteromorphic sex chromosomes revealed by the presence of a nucleolus organizer region (NOR) on the Z chromosomes [Schmid et al., 1993]. Triploid offspring (produced by blocking the extrusion of the second polar body in fertilized eggs by cold shock) can be ZZZ males, ZWW females, and ZZW. The sex of ZZW individuals can be either male $(53.8 \%)$ or female $(46.3 \% ; n=80)$, indicating that other differences, apart from sex chromosomes, could be responsible for sex differentiation [Ohta et al., 1999]. Alternatively, if sex determination in ZZW cannot tilt the balance to favour the male or the female pathway (the female-determining gene on the $\mathrm{W}$ is not able to trigger ovarian differentiation when $2 \mathrm{Z}$ chromosomes are present, nor can $2 \mathrm{Z}$ chromosomes trigger male differentiation in the presence of a $\mathrm{W}$ chromosome), sexual differentiation could proceed randomly in either a male or female direction [Kobel and Pasquier, 1986; Perrin, 2016]. In this regard, it would be of interest to see if ZZW triploid males are insensible to hormone-induced sex reversal in the same way as ZZ males [Ohta, 1987].

\section{Gonadal Differentiation}

The process of gonadal differentiation from a bipotential primordium, including the main differences between germ cell specification in anuran and urodele, has been thoroughly reviewed before [Hayes, 1998; Flament, 2016]. It is interesting to note that not all amphibian species have differentiated gonads at metamorphosis. According to the patterns of gonadal differentiation observed at metamorphosis, 3 categories or sex races can be established, namely: differentiated (well-differentiated ovaries and testes are observed at metamorphosis), undifferentiated (100\% tadpoles have ovaries at metamorphosis, males will later replace ovaries by testes), and semi-differentiated (at metamorphosis tadpoles with variable percentage of ovaries, testes, and undifferentiated gonads are present) [Witschi, 1930]. The existence of sex races in some species should be taken into account when the sex of the tadpoles is established based on the morphology of the gonads at metamorphosis, since this estimation will not be correct in semi- or undifferentiated races. Sex races are heritable, and their geographical distribution may be correlated with temperature and climatic regions [Witschi, 1930].

The genes involved in gonadal differentiation are largely conserved in vertebrates. Many genes involved in gonadal differentiation in mammals (Dmrt1, Sox9, Foxl2, Amh, Dax1, Sf1, etc.) have homologues in amphibians that are expressed during gonadal development. Howev- 
er, spatial and temporal differences in the expression of these genes suggest that the gene regulatory networks involved in gonadal differentiation are different, even between closely related species. An extensive analysis of the process of gonadal determination and differentiation in a larger number of species will still be necessary before we have a clear picture of the gene network that results in 2 antagonistic differentiation pathways that end with the establishment of male and female gonads.

Gonadal differentiation is extremely flexible and can be manipulated by hormones and other exogenous factors. The manipulation of the steroidogenic pathway affects sexual differentiation in amphibians, indicating an essential role of the steroid hormones on sexual differentiation in this group [Hayes, 1998]. However, the specific role of different steroid synthetizing enzymes in gonadal differentiation and their interaction with the gene regulatory network for sex determination may be different in different species, as the effects of hormones or inhibitors on the final outcome in gonadal differentiation can be the opposite, even between closely related species or when different doses are used in the same species [for a review, including compounds and dose-effects, see Hayes, 1998].

\section{Effect of Temperature on Amphibian Sex Determination}

No amphibian species has been described to have temperature-dependent sex determination, and the available evidence suggests that sex determination is exclusively genetic under natural conditions [Hayes, 1998]. However, it is also evident in this group that temperature can affect sex determination [Dournon et al., 1990; Wallace et al., 1999; Flament et al., 2011]. What is the evidence of a temperature effect on amphibian sex determination?

\section{Evidences from Laboratory Experiments}

The effect of the temperature of the rearing water on sexual differentiation in amphibians has been analysed since the beginning of the 20th century [King, 1903, 1909]. There is numerous experimental evidence showing that high temperatures result in sex ratios biased towards males, while development at low temperatures may produce a higher frequency of females after metamorphosis (Table 1). For a detailed review on the available information on the effect of temperature on sexual differentiation, see online supplementary Table 1 (see www. karger.com/doi/10.1159/515220 for online suppl. material).
The effect of low temperatures on gonadal sex differentiation is hard to demonstrate, as most species do not survive declines in rearing temperatures. Furthermore, this should be considered with caution when it is observed. At low temperatures, a higher frequency of females could be due to male-to-female sex reversal, but this may also cause a delay in gonadal development, more evident in undifferentiated or semi-differentiated sexual races. In this case, the effect could be transient, and male differentiation would be observed when the animals reach the reproductive age.

The opposite trend, high temperature triggers female development, has been observed in a few urodelean species [Dournon et al., 1984, 1990; Sakata et al., 2005], showing that the direction of sex deviation in response to temperature is not correlated with phylogenetic relations. In fact, antagonistic effects of temperature are observed in salamanders, where opposite sex differentiation is triggered by high temperatures in 2 species of the same genus [Dorazi et al., 1995]. Thus, high temperatures $\left(>30^{\circ} \mathrm{C}\right)$ can produce ZW males in Pleurodeles walt or ZZ females in $P$. poireti [Dournon et al., 1990]. The type of heterogamety is also not correlated with thermosensitivity, and high temperatures can trigger male differentiation in species with XX/XY or ZZ/ZW sex chromosomes (Table 1; online suppl. Table 1).

Temperature has no effect on the sex ratio in X. laevis but has an interesting effect on polyploid Xenopus hybrids with a $\mathrm{W}$ chromosome from $X$. laevis. For a given combination of sex chromosomes from different Xenopus species $\left(\mathrm{W}^{\mathrm{L}} \mathrm{Z}^{\mathrm{G}} \mathrm{Z}^{\mathrm{B}}\right.$ or $\mathrm{W}^{\mathrm{L}} \mathrm{Z}^{\mathrm{L}} \mathrm{Z}^{\mathrm{L}} \mathrm{Z}^{\mathrm{G}}$, with sex chromosomes from X. laevis, X. gilli, or X. borealis), individuals have a greater probability to develop into males as temperatures decrease, while the probability of developing into females increases with temperature [Kobel and Pasquier, 1986].

The effect of temperature described in Pelophylax esculentus might seem striking as both high and low temperatures produce more males [Hertwig, 1906]. However, it should be taken into account that $P$. esculentus is a hybrid taxon maintained by hybridogenesis with $P$. lessonae or $P$. ridibundus, or as an all-hybrid population that includes triploid individuals [Christiansen and Reyer, 2009]. Under these circumstances, the results of temperature treatments could depend on the origin and the ploidy of the animals used in the analysis.

Due to inherent limitations of amphibians, most experimental studies to test the effect of temperature on sexual differentiation are based on distorted sex ratios obtained around metamorphosis. This approach can face 
Table 1. Effect of temperature on sex ratio in amphibian species

\begin{tabular}{|c|c|c|c|c|c|}
\hline Bufo bufo & $\begin{array}{l}\text { ZZ/ZW } \\
\mathrm{XX} / \mathrm{XY} ?\end{array}$ & Dif & $\mathrm{M}$ & $\mathrm{F}$ & $?$ \\
\hline Bufo japonicus & ZZ/ZW? & Dif & $\mathrm{M}$ & $?$ & ? \\
\hline Anaxyrus terrestris & $?$ & Dif & Not affected & Not affected & ? \\
\hline Euphlyctis cyanophlyctis & $?$ & Semi-dif & $\mathrm{M}$ & $?$ & $?$ \\
\hline Xenopus laevis & $\mathrm{ZZ/ZW}$ & Dif & Not affected & Not affected & No \\
\hline Xenopus polyploid hybrids & WZZ/WZZZ & Dif & Less M & More M & Yes \\
\hline Rana temporaria & $\mathrm{XX} / \mathrm{XY}$ & $?$ & M & $\mathrm{F}($ transient?) & $?$ \\
\hline Pelophylax esculentus (kl. Esculentus) & $\mathrm{XX} / \mathrm{XY}$ & ? & $\mathrm{M}$ & M & ? \\
\hline Rana japonica & $\mathrm{XX} / \mathrm{XY}$ & Dif & $\mathrm{M}$ & $?$ & $?$ \\
\hline Hynobius retardatus ${ }^{\mathrm{a}}$ & $?$ & Dif & $\mathrm{F}$ & $?$ & $?$ \\
\hline Pleurodeles waltl & $\mathrm{ZZ/ZW}$ & Dif & $\mathrm{M}$ & $\mathrm{F}$ & Yes \\
\hline Pleurodeles poireti & $\mathrm{ZZ/ZW}$ & Dif & $\mathrm{F}$ & $?$ & Yes \\
\hline Triturus cristatus & $\mathrm{XX} / \mathrm{XY}$ & $?$ & M & $\mathrm{F}$ & Yes \\
\hline Triturus carnifex & $\mathrm{XX} / \mathrm{XY}$ & ? & $\mathrm{M}$ & $\mathrm{F}$ & Yes \\
\hline
\end{tabular}

Dif, differentiated; Semi-dif, semi-differentiated. a Data from Sakata et al., [2005].

the following problems when identifying thermal effects unequivocally: (1) differential mortality cannot be ruled out; (2) phenotypic sex is established around metamorphosis and can change in some cases; (3) some data are obtained from sex races (undifferentiated, semi-differentiated, or differentiated) and they are not always clearly defined; and (4) genotypic sex is unknown in most cases, and the effects of natural temperatures can go unnoticed. As a consequence, direct evidence of sex reversal due to temperature effects is lacking, except for a few urodelean species were sex reversal has been genetically proved $(P$. waltl, $P$. poireti, Triturus cristatus, and T. carnifex) [Dournon and Houillon, 1984; Wallace and Wallace, 2000].

Limitations in the experimental design can provide the opposite results for the same species. According to the literature, Hynobius retardatus larvae reared at high temperatures can be transformed from female to male [Uchida, 1937] or can develop almost exclusively as females [Sakata et al., 2005]. These contradictory results may be due to the use of different sexual races [although this was ruled out by Sakata et al., 2005] or to an undetermined exposition time, together with an analysis of the samples before metamorphosis in the first case.

Effect of Temperature in Amphibian Sex Differentiation
With some interesting exceptions, high temperatures in amphibians are masculinizing, while low temperatures can be feminizing. The relation between the increase in the male sex ratio and the increase of temperature has been shown to be linear in $R$. sylvatica [Lambert et al., 2018]. This response is similar to the pattern of the few fish species with GSD affected by the temperature analysed [Ospina-Álvarez and Piferrer, 2008]. Regarding low temperature, it is not masculinizing in amphibians nor in fish with TSD [Ospina-Álvarez and Piferrer, 2008]. Thus, the pattern of the sex ratio response to the temperature observed in amphibians is similar to that described for fish [Ospina-Álvarez and Piferrer, 2008].

\section{Sex Reversal in Nature: Thermal Effects in Natural Populations?}

Although the thermal effect on sexual differentiation has been established for many amphibian species at extreme temperatures, very few studies have investigated to what extent GSD is overridden under the temperature range normally experienced by the species. The difficulty in correlating sex reversal with temperature, as well as the 
wide distribution of homomorphic chromosomes, does not facilitate the identification of temperature-induced sex-reversed individuals in natural populations.

Although there are examples of sex-reversed amphibians found in nature [Crew, 1921; Hayes, 1998], few cases have been well documented and genetically proven. A Bufo bufo (B. vulgaris) male found in amplexus was later found to have one ovotestes and one ovary. The testicular tissue was normal, but the ovarian part showed degenerated oocytes. The offspring obtained from this male $(n=$ 774) were all females, so it was proven to be an XX male [Crew, 1921]. In Hyla japonica, YY males have been captured in different locations in the wild. These males, together with spontaneous XY females (sex-reversed males) identified in the laboratory, indicate that XY males can reverse their sex in the wild, reproduce with normal XY males, and produce YY males. Furthermore, YY males are fertile and result in only male offspring when crossed with normal females [Kawamura and Nishioka, 1977].

Sex-linked genetic markers provide a useful tool to establish the genetic sex and thus to find sex-reversed individuals in nature. Using this strategy, several genotypic $\mathrm{XX}$ individuals with a male phenotype and one genotypic $\mathrm{XY}$ individual with a female phenotype have been identified in natural populations of $R$. temporaria [Alho et al., 2010; Rodrigues et al., 2018]. A different study in $R$. calamitans detected high frequencies of sex reversal in several populations (2-16\%) [Lambert et al., 2019]. Interestingly, sex reversal was not correlated with land use and human-associated contamination, suggesting an important role of environmental changes in species with long metamorphosis (ca. 1 year) and maturing (1-2 years post metamorphosis) periods.

\section{Molecular Mechanisms Mediating Temperature Effects in Sex Differentiation}

How does temperature affect sex differentiation in amphibian species with GSD? Does temperature work through the same pathways used by genetic factors? Is temperature-induced sex reversal in amphibians triggered throughout the same pathways as those described in fish or reptile species with TSD? What is the ultimate link between temperature and the gene regulatory network for sex determination? Below, we reviewed some intermediate players and direct links between temperature and changes in the expression of sex related genes, showing a lack of information about these molecular mechanisms in the class Amphibia.

\section{Steroidogenic Pathway}

Steroidogenesis and/or steroid hormone signalling pathways are affected by thermal treatment in amphibians. Feminizing temperatures increase Cyp 19a1 expression, triggering an acceleration of ovarian differentiation through increased estrogen levels, while masculinizing temperatures inhibit Cyp19a1 and Dmrt1 upregulation [Guiguen et al., 2010]. The differential expression of steroidogenic enzymes is observed in R. rugosa before the onset of gonadal differentiation. Transcription levels of Cyp19a1 or Cyp17 are higher in undifferentiated ZW or ZZ gonads, respectively [Maruo et al., 2008], and are correlated with their activity [Sakurai et al., 2008; Isomura et al., 2011]. Furthermore, male expression profiles (Cyp17 upregulation and Cyp19a1 downregulation) are observed in XX sex-reversed $R$. rugosa males [Iwade et al., 2008].

The effect of temperature on steroid synthesis has also been described in $P$. waltl, where an increase in temperature reduces ERa expression in $\mathrm{ZW}$ larvae $\left(32^{\circ} \mathrm{C}\right.$ produces ZW males), while the addition of estradiol inhibits temperature-induced sex reversal in ZW females [Zaborski, 1986; Ko et al., 2008]. Accordingly, Cyp19a1 expression levels are higher in the ZW gonads compared with the ZZ or sex-reversed ZW gonads. However, in this species, the differences are not evident in undifferentiated gonads but just at the beginning of the differentiation, which coincides with the end of the temperature sensitivity period [Chardard et al., 1995; Kuntz et al., 2003]. A similar situation has been described in the salamander $H$. retardatus, where Cyp19a1 shows a sexually dimorphic expression before the morphological differentiation, with higher levels also in females (including sex-reversed genotypic males obtained by the feminizing effect of the increased temperature) [Sakata et al., 2005]. Interestingly, in $P$. walt and $H$. retardatus, the same external cue (increase of temperature to $30-32^{\circ} \mathrm{C}$ or $28^{\circ} \mathrm{C}$, respectively) causes a different effect on Cyp 19a1 (decrease or increase levels, respectively) and thus has a different effect on gonadal differentiation (testis or ovary differentiation, respectively).

The late onset of the sexually dimorphic expression of Cyp19a1 in some species, including fish and reptiles, indicates that this gene may not have a pivotal regulatory step linking temperature with gonadal differentiation [Desvages and Pieau, 1992; Murdock and Wibbels, 2003]. Furthermore, in reptiles, it has been shown that the expression patterns of ovaries obtained at female-producing temperatures are not equivalent to those of ovaries induced by estrogen treatments [Canesini et al., 2018]. 


\section{Epigenetic Regulation}

Changes in DNA methylation patterns have been correlated with temperature effects on sex differentiation. Male-producing temperatures in fish and reptile species are associated with increased DNA methylation in the promoter of cyp19a1 (prevents the binding of transcriptional activators such as Sf1 and Foxl2) and with decreased expression levels [Navarro-Martín et al., 2011; Venegas et al., 2016; Liu et al., 2019], thus linking environmental signals with sex determination. An inverse relationship between DNA methylation and gene expression was also identified in Dmrt1 but not in Amh or Foxl2 promoters [Piferrer et al., 2019]. In fact, the downregulation of Dmrt1 and upregulation of Cyp19a1 are observed in $H$. retardatus when sex reversal from genetic males to phenotypic females is induced by high temperature [Sakata et al., 2006]. A comparative analysis between the Drmt1 promoter in vertebrate species revealed the elimination of the non-coding exon 1 in the homeotherms, suggesting that the regulatory sequences in this region could be involved in the temperature sensitivity of Dmrt 1 in endothermic vertebrates [Mawaribuchi et al., 2012]. Further functional studies on these sequences are needed to establish their role in Dmrt1 sensitivity to temperature. Data on temperature-induced changes in DNA methylation in the genes involved in sex development in amphibians are still lacking. Furthermore, there is no information about the transgenerational epigenetic inheritance of sex reversal in this group, although it has been described in fish and reptiles [Warner et al., 2013; Shao et al., 2014].

Other epigenetic modifications connect temperature and sex determination. In the red-eared slider turtle, Trachemys scripta, a low temperature increases the transcription of $K d m 6 b$ (lysine-specific demethylase 6B), a chromatin modifier gene that eliminates the trimethylation of H3K27 in the promoter of Dmrt1, upregulating its expression and promoting male development [Ge et al., 2018]. The landscape may be more complex, as species- and sex-specific temperature profiles cause intron retention in 2 members of the Jumonji gene family (Jarid 2 and $K d m 6 b)$ in Alligator mississippiensis, T. scripta, and Pogona vitticeps [Deveson et al., 2017]. It has been suggested that intron retention may change the targets of gene silencing, gene activation, and recruitment of chromatin remodelling complexes [Georges and Holleley, 2018]. Again, no information about the thermal effect on epigenetic modifications or chromatin modifiers is available in amphibian species. It will be of great interest to know if the pathways described for the temperature-me-

Effect of Temperature in Amphibian Sex Differentiation diated effect on gonadal differentiation in fish and reptiles are conserved in amphibian species with a thermal effect on sexual development.

\section{Molecular Target of Temperature - CaRe Model}

The link between temperature and epigenetic modifications has been established in T. scripta, where an increase in temperature has been associated with an increase in $\mathrm{Ca}^{2+}$ influx. This signal is transduced by the phosphorylation of STAT3 (signal transducer and activator of transcription 3), which in turn inhibits $K d m 6 b$ transcription, promoting female development by preventing the activation of the Dmrt1 promoter [Weber et al., 2020].

Temperature can affect gene expression through epigenetic regulation, although the exact mechanism is still lacking for most species. A model has recently been proposed whereby temperature cues or other environmental signals can be sensed by the cell through the calcium and redox status and can be transduced by different mechanisms into the differential expression of the genes involved in sexual development [Castelli et al., 2020].

\section{Evolutionary Implications}

Why do amphibians retain sensitivity to temperature (and steroids) while having a clear GSD? The environmental effect of temperature on sexual differentiation in amphibians is similar to that observed in some lizards with GSD; sex chromosomes control gonadal differentiation at middle temperatures, while temperature takes over when temperatures are extreme [Quinn et al., 2007; Radder et al., 2008].

The adaptive-coexistence model predicts that a species with environmental and genetic effects on sex determination should exhibit the most extreme sex-specific fitness effects in the temperature range that overrides GSD [Bull, 2008]. In amphibians, although with some exceptions, high temperatures transform genotypic females into phenotypic males. In this group, temperature is also closely related to growth, so the rearing temperature can have an important influence not only on offspring sex ratios but also on sex-specific development and fecundity [Lambert et al., 2018]. As a general rule, higher temperatures accelerate development, probably by increasing the metabolic activity of tadpoles, but they also decrease size at metamorphosis because of the shortening of the time needed for development [Álvarez and Nicieza, 2002; GomezMestre et al., 2010]. Accordingly, genotypic females pro- 


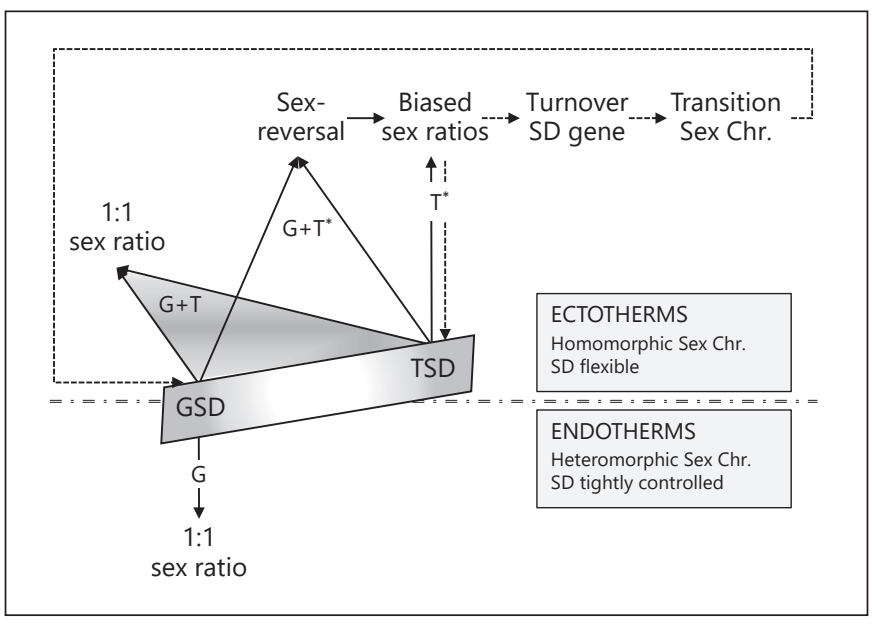

Fig. 1. Simplified model to explain the effects of temperature-induced sex reversal on the evolution of sex-determining genes and sex chromosomes in ectotherms compared with endotherms. T*, extreme temperature.

duced at high temperatures will have a lower size and a reduced fecundity [Sibly and Atkinson, 1994]. Thus, overriding their genotypic sex and reversing into males could maximize their fitness. It would be of interest to see if more females are produced at high temperatures in species with increased body size when reared at a higher temperature, like Rhinella granulosa [Maciel and Juncá, 2009].

Experimental evidence has revealed that environmental sex reversal in amphibians may be a more widespread phenomenon than initially suspected, with consequences in sex ratios and in sex chromosome evolution [Alho et al., 2010; Rodrigues et al., 2018; Lambert et al., 2019]. Thus, an increase in rearing temperature can lead to a shortage of genotypic males, which will promote the frequency-dependent selection of males and the emergence of a new sex-determining gene [Wedekind, 2010].

In this way, sex reversal and gene-environment interactions may be involved in the extreme lability of the sex determination mechanisms observed in amphibians, promoting switching between sex-determining genes and homomorphic sex chromosomes [Dufresnes et al., 2015]. On the other hand, sex reversal can promote recombination between the heteromorphic pair, maintaining homomorphic sex chromosomes [Perrin, 2009; Rodrigues et al., 2018]. Closing the circle, homomorphic sex chromosomes eliminate a major barrier to functional sex reversal, namely the fitness of YY or WW genotypes (Fig. 1). In fact, sex reversal in amphibians is not always in the homogametic sex (Table 1; suppl. Table 1) as opposed to what has been described in lizards with GSD [Quinn et al., 2007; Radder et al., 2008]. The high prevalence of homomorphic sex chromosomes in this group allows for the survival of YY or WW individuals if they are produced, as has been demonstrated in P. waltl [Dournon and Houillon, 1984]. According to this, flexibility in sexual differentiation in ectotherms allows for responding to changing environments, a situation in which it is beneficial to have homomorphic sex chromosomes. On the other hand, the stricter control of sex differentiation in endotherms allows for the differentiation of sex chromosomes and prevents any subsequent turnover [Francis, 1992].

Labile sex-determining mechanisms may be an advantage in changing environments but also a problem in the face of a global temperature change. The linear relationship between increased temperatures and skewed sex ratios observed in R. sylvatica [Lambert et al., 2018] reveals that even modest changes in temperature may cause sex reversal in amphibians. However, with a predicted temperature rise between 3 and $5^{\circ} \mathrm{C}$ by the end of the next century [Hausfather and Peters, 2020], skewed sex ratios represent a risk for species with a thermal influence on GSD.

\section{Conclusions}

Temperature can override GSD in amphibians, and the effects of temperature in the form of temperatureinduced sex reversal may be more common than initially thought in this group. Only about $0.23 \%$ of amphibian species have been examined for their response to incubation temperature (19 out of 8,330 species). The importance and evolution of temperature-mediated sex reversal in this group are not fully understood. This lack of knowledge represents a starting point to fill the gaps in the evolution of sex chromosomes and for sex determination in vertebrates.

\section{Conflict of Interest Statement}

The authors have no conflicts of interest to declare. 


\section{Funding Sources}

This work was supported by the Spanish Ministerio de Ciencia, Innovación y Universidades (grant number BFU2016-78001-P) (cofunded by the European Regional Development Fund), by the Junta de Andalucía (programme "Ayudas a grupos de investigación” (group RNM-924), and by the Universidad de Jaén (programme Plan de Apoyo a la Investigación, Acción 1).

\section{Author Contributions}

All authors were involved in writing and discussing the contents of the article.

\section{References}

Alho JS, Matsuba C, Merilä J. Sex reversal and primary sex ratios in the common frog (Rana temporaria). Mol Ecol. 2010;19(9):1763-73.

Álvarez D, Nicieza AG. Effects of temperature and food quality on anuran larval growth and metamorphosis. Funct Ecol. 2002;16(5):6408.

Bewick AJ, Anderson DW, Evans BJ. Evolution of the closely related, sex-related genes DM-W and DMRT1 in African clawed frogs (Xenopus). Evolution. 2011;65(3):698-712.

Bull JJ. Sex determination: Are two mechanisms better than one? J Biosci. 2008;33(1):5-8.

Canesini G, Stoker C, Galoppo GH, Durando ML, Tschopp MV, Luque EH, et al. Temperaturevs. estrogen-induced sex determination in Caiman latirostris embryos: Both females, but with different expression patterns of key molecules involved in ovarian development. Gen Comp Endocrinol. 2018;259:176-88.

Castelli MA, Whiteley SL, Georges A, Holleley CE. Cellular calcium and redox regulation: the mediator of vertebrate environmental sex determination? Biol Rev Camb Philos Soc. 2020;95(3):680-95.

Chang CY, Witschi E. Genic control and hormonal reversal of sex differentiation in Xenopus. Proc Soc Exp Biol Med. 1956;93(1):140-4.

Chardard D, Desvages G, Pieau C, Dournon C. Aromatase activity in larval gonads of Pleurodeles waltl (Urodele Amphibia) during normal sex differentiation and during sex reversal by thermal treatment effect. Gen Comp Endocrinol. 1995;99(1):100-7.

Christiansen DG, Reyer HU. From clonal to sexual hybrids: Genetic recombination via triploids in all-hybrid populations of water frogs. Evolution. 2009;63(7):1754-68.

Crew FAE. Sex-reversal in frogs and toads. A review of the recorded cases of abnormality of the reproductive system and an account of a breeding experiment. J Genet. 1921;11(2): $141-81$.

Desvages G, Pieau C. Aromatase activity in gonads of turtle embryos as a function of the incubation temperature of eggs. J Steroid Biochem Mol Biol. 1992;41(3-8):851-3.

Deveson IW, Holleley CE, Blackburn J, Marshall Graves JA, Mattick JS, Waters PD, et al. Differential intron retention in Jumonji chromatin modifier genes is implicated in reptile temperature-dependent sex determination. Sci Adv. 2017;3(6):e1700731.
Dorazi R, Chesnel A, Dournon C. Opposite sex determination of gonads in two pleurodeles species may be due to a temperature-dependent inactivation of sex chromosomes. J Hered. 1995;86(1):28-31.

Dournon C, Houillon C. Démonstration génétique de l'inversion fonctionnelle du phénotype sexuel femelle sous l'action de la température d'élevage chezl'Amphibien Urodèle : Pleurodeles waltlii Michah. Reprod Nutr Développement. 1984;24:361-78.

Dournon C, Guillet F, Boucher D, Lacroix JC. Cytogenetic and genetic evidence of male sexual inversion by heat treatment in the newt Pleurodeles poireti. Chromosoma. 1984; 90(4):261-4.

Dournon C, Houillon C, Pieau C. Temperature sex-reversal in amphibians and reptiles. Int $\mathrm{J}$ Dev Biol. 1990;34(1):81-92.

Dufresnes C, Borzée A, Horn A, Stöck M, Ostini $\mathrm{M}$, Sermier R, et al. Sex-chromosome homomorphy in palearctic tree frogs results from both turnovers and $\mathrm{X}-\mathrm{Y}$ recombination. $\mathrm{Mol}$ Biol Evol. 2015;32(9):2328-37.

Eggert C. Sex determination: the amphibian models. Reprod Nutr Dev. 2004;44(6):539-49.

Flament S. Sex reversal in amphibians. Sex Dev. 2016;10(5-6):267-78.

Flament S, Chardard D, Chesnel A, Dumond H. Sex determination and sexual differentiation in amphibians. Horm Reprod Vertebr. 2011; 2:1-19.

Francis RC. Sexual liability in teleosts: developmental factors. Quaterly Rev Biol. 1992;67: $1-18$

Fujii J, Kodama M, Oike A, Matsuo Y, Min MS, Hasebe T, et al. Involvement of androgen receptor in sex determination in an amphibian species. PLoS One. 2014;9(5):e93655.

Furman BLS, Evans BJ. Divergent Evolutionary trajectories of two young, homomorphic, and closely related sex chromosome systems. Genome Biol Evol. 2018;10(3):742-55.

Furman BLS, Cauret CMS, Knytl M, Song XY, Premachandra T, Ofori-Boateng C, et al. A frog with three sex chromosomes that comingle together in nature: Xenopus tropicalis has a degenerate $\mathrm{W}$ and a $\mathrm{Y}$ that evolved from a Z chromosome. PLoS Genet. 2020;16(11): e1009121.

Ge C, Ye J, Weber C, Sun W, Zhang H, Zhou Y, et al. The histone demethylase KDM6B regulates temperature-dependent sex determina- tion in a turtle species. Science. 2018; 360(6389):645-8.

Georges A, Holleley CE. How does temperature determine sex? Science. 2018;360(6389):6012.

Gomez-Mestre I, Saccoccio VL, Iijima T, Collins EM, Rosenthal GG, Warkentin KM. The shape of things to come: linking developmental plasticity to post-metamorphic morphology in anurans. J Evol Biol. 2010;23(7):136473.

Green DM. Cytogenetics of the endemic New Zealand frog, Leiopelma hochstetteri: extraordinary supernumerary chromosome variation and a unique sex-chromosome system. Chromosoma. 1988;97(1):55-70.

Guiguen Y, Fostier A, Piferrer F, Chang CF. Ovarian aromatase and estrogens: a pivotal role for gonadal sex differentiation and sex change in fish. Gen Comp Endocrinol. 2010;165(3): 352-66.

Hausfather Z, Peters GP. Emissions - the "business as usual" story is misleading. Nature. 2020;577(7792):618-20.

Hayes TB. Sex determination and primary sex differentiation in amphibians: genetic and developmental mechanisms. J Exp Zool. 1998; 281(5):373-99.

Hertwig R. Weitere Untersuchungen über das Sexualitätsproblem. Verh Deutsch Zool Gesellsch. 1906:186-213.

Hillis DM, Green DM. Evolutionary changes of heterogametic sex in the phylogenetic history of amphibians. J Evolution Biol. 1990;3(1-2): $49-64$.

Isomura T, Haraguchi S, Miyamoto K, Tsutsui K, Nakamura Y, Nakamura M. Estrogen biosynthesis in the gonad of the frog Rana rugosa. Gen Comp Endocrinol. 2011;170(1):207-12.

Iwade R, Maruo K, Okada G, Nakamura M. Elevated expression of P450c17 (CYP17) during testicular formation in the frog. Gen Comp Endocrinol. 2008;155(1):79-87.

Jeffries DL, Lavanchy G, Sermier R, Sredl MJ, Miura I, Borzée A, et al. A rapid rate of sex-chromosome turnover and non-random transitions in true frogs. Nat Commun. 2018;9(1): 4088 .

Kawamura T, Nishioka M. Aspects of the reproductive biology of Japanese anurans. In: Taylor DH Guttman SI (eds). The Reproductive Biology of Amphibians. New York: Plenum Press; 1977. p. 103-39. 
King HD. The effects of heat on the development of the toad's egg. Biol Bull. 1903;5(4):218-32.

King HD. Studies on sex-determination in amphibians. II. Biol Bull. 1909; XV:27-43.

Ko CI, Chesnel A, Mazerbourg S, Kuntz S, Flament S, Chardard D. Female-enriched expression of ERalpha during gonad differentiation of the urodele amphibian Pleurodeles waltl. Gen Comp Endocrinol. 2008;156(2): 234-45.

Kobel HR, Du Pasquier L. Genetics of polyploid Xenopus. Trends Genet. 1986;2:310-5.

Kuntz S, Chesnel A, Duterque-Coquillaud M, Grillier-Vuissoz I, Callier M, Dournon C, et al. Differential expression of P450 aromatase during gonadal sex differentiation and sex reversal of the newt Pleurodeles waltl. J Steroid Biochem Mol Biol. 2003;84(1):89-100.

Lambert MR, Smylie MS, Roman AJ, Freidenburg LK, Skelly DK. Sexual and somatic development of wood frog tadpoles along a thermal gradient. J Exp Zool. 2018;329(2):72-9.

Lambert MR, Tran T, Kilian A, Ezaz T, Skelly DK. Molecular evidence for sex reversal in wild populations of green frogs (Rana clamitans). PeerJ. 2019;7:e6449.

Liu J, Liu X, Jin C, Du X, He Y, Zhang Q. Transcriptome profiling insights the feature of sex reversal induced by high temperature in tongue sole cynoglossus semilaevis. Front Genet. 2019;10:1-15.

Maciel TA, Juncá FA. Effects of temperature and volume of water on the growth and development of tadpoles of Pleurodema diplolister and Rhinella granulosa (Amphibia: Anura). Zoologia (Curitiba, Impr.). 2009;26(3):413-8.

Maruo K, Suda M, Yokoyama S, Oshima Y, Nakamura M. Steroidogenic gene expression during sex determination in the frog Rana rugosa. Gen Comp Endocrinol. 2008;158(1): 87-94.

Mawaribuchi S, Yoshimoto S, Ohashi S, Takamatsu N, Ito M. Molecular evolution of vertebrate sex-determining genes. Chromosome Res. 2012;20(1):139-51.

Mawaribuchi S, Takahashi S, Wada M, Uno Y, Matsuda Y, Kondo M, et al. Sex chromosome differentiation and the $\mathrm{W}$ - and Z-specific loci in Xenopus laevis. Dev Biol. 2017;426(2):393400.

Mikamo K, Witschi E. Masculinization and breeding of the WW Xenopus. Experientia. 1964;20(11):622-3.

Mikamo K, Witschi E. The mitotic chromosomes in Xenopus laevis (Daudin): Normal, sex reversed and female WW. Cytogenetics. 1966; 5(1):1-19.

Miura I. Sex determination and sex chromosomes in amphibia. Sex Dev. 2017;11(5-6):298-306.

Miura I, Ohtani H, Nakamura M, Ichikawa Y, Saitoh $\mathrm{K}$. The origin and differentiation of the heteromorphic sex chromosomes $\mathrm{Z}, \mathrm{W}, \mathrm{X}$, and $\mathrm{Y}$ in the frog Rana rugosa, inferred from the sequences of a sex-linked gene, ADP/ATP translocase. Mol Biol Evol. 1998; 15(12):1612-9.

Murdock C, Wibbels T. Cloning and expression of aromatase in a turtle with temperature-de- pendent sex determination. Gen Comp Endocrinol. 2003;130(2):109-19.

Navarro-Martín L, Viñas J, Ribas L, Díaz N, Gutiérrez A, Di Croce L, et al. DNA methylation of the gonadal aromatase (cyp19a) promoter is involved in temperature-dependent sex ratio shifts in the European sea bass. PLoS Genet. 2011;7(12):e1002447.

Nishioka M, Hanada H. Sex of reciprocal hybrids between the Hamakita (XX-XY Type) population and the Murakami (ZW-ZZ Type) population of Rana rugosa. Sci Rep Lab Amphib Biol, Hiroshima Univ. 1994;13.

Ogata M, Lee JY, Kim S, Ohtani H, Sekiya K, Igarashi $\mathrm{T}$, et al. The prototype of sex chromosomes found in Korean populations of Rana rugosa. Cytogenet Genome Res. 2002;99(14):185-93.

Ogata M, Hasegawa Y, Ohtani H, Mineyama M, Miura I. The ZZ/ZW sex-determining mechanism originated twice and independently during evolution of the frog, Rana rugosa. Heredity. 2008;100(1):92-9.

Ogata M, Lambert M, Ezaz T, Miura I. Reconstruction of female heterogamety from admixture of XX-XY and ZZ-ZW sex-chromosome systems within a frog species. Mol Ecol. 2018;27(20):4078-89.

Ohta S. Sex determining mechanism in Buergeria buergeri (Schlegel) II. The effects of sex hormones on the differentiation of gonads and the offspring of sex-reversed females. Sci Rep Lab Amphib Biol, Hiroshima Univ. 1987;9: 213-38.

Ohta S, Sumida M, Nishioka M. Sex-determining mechanism in Buergeria buergeri (Anura, Rhacophoridae). III. Does the ZZW triploid frog become female or male? J Exp Zool. 1999; 283(3):295-306.

Oike A, Kodama M, Yasumasu S, Yamamoto T, Nakamura Y, Ito E, et al. Participation of androgen and its receptor in sex determination of an amphibian species. PLoS One. 2017a; 12(6): e0178067-16.

Oike A, Watanabe K, Min M-S, Tojo K, Kumagai M, Kimoto Y, et al. Origin of sex chromosomes in six groups of Rana rugosa frogs inferred from a sex-linked DNA marker. J Exp Zool. 2017b;327(7):444-52.

Okada E, Yoshimoto S, Ikeda N, Kanda H, Tamura K, Shiba T, et al. Xenopus W-linked DM-W induces Foxl2 and Cyp19 expression during ovary formation. Sex Dev. 2009;3(1):38-42.

Ospina-Álvarez N, Piferrer F. Temperature-dependent sex determination in fish revisited: Prevalence, a single sex ratio response pattern, and possible effects of climate change. PLoS One. 2008;3(7):e2837-4.

Perrin N. Sex reversal: a fountain of youth for sex chromosomes? Evolution. 2009;63(12):3043-9.

Perrin N. Random sex determination: When developmental noise tips the sex balance. BioEssays. 2016;38(12):1218.

Phillips BC, Rodrigues N, Jansen van Rensburg A, Perrin N. Phylogeography, more than elevation, accounts for sex chromosome differentiation in Swiss populations of the common frog (Rana temporaria). Evolution. 2020;74: 644-54.

Piferrer F, Anastasiadi D, Valdivieso A, SánchezBaizán N, Moraleda-Prados J, Ribas L. The model of the conserved epigenetic regulation of sex. Front Genet. 2019;10:1-13.

Quinn AE, Georges A, Sarre SD, Guarino F, Ezaz T, Graves JA. Temperature sex reversal implies sex gene dosage in a reptile. Science. 2007;316(5823):411.

Radder RS, Quinn AE, Georges A, Sarre SD, Shine R. Genetic evidence for co-occurrence of chromosomal and thermal sex-determining systems in a lizard. Biol Lett. 2008;4(2):176-8.

Roco ÁS, Olmstead AW, Degitz SJ, Amano T, Zimmerman LB, Bullejos M. Coexistence of $\mathrm{Y}, \mathrm{W}$, and $\mathrm{Z}$ sex chromosomes in Xenopus tropicalis. Proc Natl Acad Sci USA. 2015; 112(34):E4752-61.

Rodrigues N, Studer T, Dufresnes C, Perrin N. Sex-chromosome recombination in common frogs brings water to the fountain-of-youth. Mol Biol Evol. 2018;35(4):942-8.

Sakata N, Tamori Y, Wakahara M. P450 aromatase expression in the temperature-sensitive sexual differentiation of salamander (Hynobius retardatus) gonads. Int J Dev Biol. 2005; 49(4):417-25.

Sakata N, Miyazaki K, Wakahara M. Up-regulation of P450arom and down-regulation of Dmrt-1 genes in the temperature-dependent sex reversal from genetic males to phenotypic females in a salamander. Dev Genes Evol. 2006;216(4):224-8.

Sakurai N, Maruo K, Haraguchi S, Uno Y, Oshima $\mathrm{Y}$, Tsutsui K, et al. Immunohistochemical detection and biological activities of CYP17 (P450c17) in the indifferent gonad of the frog Rana rugosa. J Steroid Biochem Mol Biol. 2008;112(1-3):5-12.

Schmid M, Steinlein C. Sex chromosomes, sexlinked genes, and sex determination in the vertebrate class amphibia. In: Scherer G, Schmid M, editors. Genes and Mechanisms in Vertebrate Sex Determination. Basel/Switzerland: Birkhäuser Verlag; 2001. p. 143-76.

Schmid M, Ohta S, Steinlein C, Guttenbach M. Chromosome banding in Amphibia. XIX. Primitive ZW/ZZ sex chromosomes in Buergeria buergeri (Anura, Rhacophoridae). $\mathrm{Cy}$ togenet Cell Genet. 1993;62(4):238-46.

Schmid M, Steinlein C, Bogart JP, Feichtinger W, León P, La Marca E, et al. The chromosomes of terraranan frogs: Insights into vertebrate cytogenetics. Cytogenet Genome Res. 2010; 130-131:1-568.

Shao C, Li Q, Chen S, Zhang P, Lian J, Hu Q, et al. Epigenetic modification and inheritance in sexual reversal of fish. Genome Res. 2014; 24(4):604-15.

Sibly RM, Atkinson D. How rearing temperature affects optimal adult size in ectotherms. Funct Ecol. 1994;8(4):486-93.

Uchida T. Studies on the Sexuality of Amphibia. III. Sex-transformation in Hynobius retardatus by the function of high temperature. J Fac Sci Hokkaido Imp Univ. 1937;6:59-70. 
Uno Y, Nishida C, Oshima Y, Yokoyama S, Miura I, Matsuda Y, et al. Comparative chromosome mapping of sex-linked genes and identification of sex chromosomal rearrangements in the Japanese wrinkled frog (Rana rugosa, Ranidae) with ZW and XY sex chromosome systems. Chromosome Res. 2008; 16(4):637-47.

Valenzuela N, Lance VA. Temperature-Dependent Sex Determination in Vertebrates. Washington: Smithsonian Books; 2004.

Venegas D, Marmolejo-Valencia A, ValdesQuezada C, Govenzensky T, Recillas-Targa F, Merchant-Larios H. Dimorphic DNA methylation during temperature-dependent sex determination in the sea turtle Lepidochelys olivacea. Gen Comp Endocrinol. 2016;236: $35-41$.

Wallace $\mathrm{H}$, Wallace BM. Sex reversal of the newt Triturus cristatus reared at extreme temperatures. Int J Dev Biol. 2000;44(7):807-10.
Wallace H, Badawy GM, Wallace BM. Amphibian sex determination and sex reversal. Cell Mol Life Sci. 1999;55(6-7):901-9.

Warner DA, Uller T, Shine R. Transgenerational sex determination: the embryonic environment experienced by a male affects offspring sex ratio. Sci Rep. 2013;3:2709.

Weber C, Zhou Y, Lee JG, Looger LL, Qian G, Ge $\mathrm{C}$, et al. Temperature-dependent sex determination is mediated by pSTAT3 repression of Kdm6b. Science. 2020;368(6488):303-6.

Wedekind C. Searching for sex-reversals to explain population demography and the evolution of sex chromosomes. Mol Ecol. 2010; 19(9):1760-2.

Witschi E. Studies on sex differentiation and sex determination in amphibians. IV. The geographical distribution of the sex races of the European grass frog (Rana temporaria, L.). A contribution to the problem of the evolution of sex. J Exp Zool. 1930;56(2):149-65.
Yokoyama S, Oshima Y, Tokita J, Suda M, Shinozuka T, Nakamura M. Androgen receptor of the frog Rana rugosa: molecular cloning and its characterization. J Exp Zool A Ecol Genet Physiol. 2009;311(10):796-812.

Yoshimoto S, Okada E, Umemoto H, Tamura K, Uno Y, Nishida-umehara C, et al. A W-linked $\mathrm{DM}$-domain gene, DM-W, participates in primary ovary development in Xenopus laevis. Proc Natl Acad Sci USA. 2008;105(7): 2469-74.

Yoshimoto S, Ikeda N, Izutsu Y, Shiba T, Takamatsu N, Ito M. Opposite roles of DMRT1 and its W-linked paralogue, DM-W, in sexual dimorphism of Xenopus laevis: implications of a ZZ/ZW-type sex-determining system. Development. 2010;137(15):2519-26.

Zaborski P. Temperature and estrogen dependent changes of sex phenotype and $\mathrm{H}-\mathrm{Y}$ antigen expression in gonads of a newt. Prog Clin Biol Res. 1986;217A:163-9. 